\title{
Exercise Training Attenuates the Dysregulated Expression of Adipokines and Oxidative Stress in White Adipose Tissue
}

\author{
Takuya Sakurai, ${ }^{1}$ Junetsu Ogasawara, ${ }^{1}$ Ken Shirato, ${ }^{1}$ Tetsuya Izawa, ${ }^{2}$ Shuji $\mathrm{Oh}$-ishi, ${ }^{3}$ \\ Yoshinaga Ishibashi, ${ }^{1}$ Zsolt Radák, ${ }^{4}$ Hideki Ohno, ${ }^{5}$ and Takako Kizaki ${ }^{1}$ \\ ${ }^{1}$ Department of Molecular Predictive Medicine and Sport Science, Kyorin University, School of Medicine, 6-20-2 Shinkawa, \\ Mitaka, Tokyo, Japan \\ ${ }^{2}$ Department of Sports Biochemistry, Faculty of Health and Sport Science, Doshisha University, 1-3 Tatara Miyakodani, \\ Kyotanabe, Kyoto, Japan \\ ${ }^{3}$ National Hospital Organization Ibarakihigashi National Hospital, The Center of Chest Diseases and Severe Motor and \\ Intellectual Disabilities, Terunuma 825, Tokai-mura, Naka-gun, Ibaraki, Japan \\ ${ }^{4}$ Institute of Sport Science, University of Physical Education, Alkotas u. 44, TF, Budapest, Hungary \\ ${ }^{5}$ Social Medical Corporation, The Yamatokai Foundation, Nangai, Higashiyamato, Tokyo, Japan
}

Correspondence should be addressed to Takuya Sakurai; sakutaku@ks.kyorin-u.ac.jp

Received 29 September 2016; Accepted 25 December 2016; Published 12 January 2017

Academic Editor: Saeid Golbidi

Copyright (C) 2017 Takuya Sakurai et al. This is an open access article distributed under the Creative Commons Attribution License, which permits unrestricted use, distribution, and reproduction in any medium, provided the original work is properly cited.

\begin{abstract}
Obesity-induced inflammatory changes in white adipose tissue (WAT), which caused dysregulated expression of inflammationrelated adipokines involving tumor necrosis factor- $\alpha$ and monocyte chemoattractant protein-1, contribute to the development of insulin resistance. Moreover, current literature reports state that WAT generates reactive oxygen species (ROS), and the enhanced production of ROS in obese WAT has been closely associated with the dysregulated expression of adipokines in WAT. Therefore, the reduction in excess WAT and oxidative stress that results from obesity is thought to be one of the important strategies in preventing and improving lifestyle-related diseases. Exercise training (TR) not only brings about a decrease in WAT mass but also attenuates obesity-induced dysregulated expression of the adipokines in WAT. Furthermore, some reports indicate that TR affects the generation of oxidative stress in WAT. This review outlines the impact of TR on the expression of inflammation-related adipokines and oxidative stress in WAT.
\end{abstract}

\section{Introduction}

In recent years, obesity due to hypertrophy of adipocytes caused by a lack of physical exercise and high-calorie diets has greatly increased in the world and has become a serious social problem [1]. The world obesity population has rapidly increased for the past 40 years, and now $10.8 \%$ of male adults (266 million) and $14.9 \%$ of female adults ( 375 million) are obese. If the trend continues, $18 \%$ of male adults and $21 \%$ of female adults will be obese by 2025 [2]. It is widely known that obesity is a risk factor for the development of lifestyle-related diseases such as type 2 diabetes and hyperlipidemia and that obesity and type 2 diabetes are responsible for an increase in arteriosclerotic disease $[3,4]$. The number of diabetic patients has increased worldwide to reach 422 million, which is a fourfold increase in approximately 35 years [5]. As mentioned above, the worldwide increase in the number of obese people and in lifestyle-related disease patients is a serious problem, and this is true from the aspect of personal suffering as well as from the economical aspect of medical costs. As obesity increases, medical costs related to it logically rise. For instance, medical costs related to obesity reached 147 billion dollars in the US in 2008, and annual medical costs for obese people are on average 1,429 dollars higher than costs for people whose weight is standard, indicating a need to establish effective strategies for the prevention and improvement of obesity and lifestyle-related diseases [6]. Accordingly, solving the mechanism of diabetic development and establishing strategies for the prevention and improvement of obesity and type 2 diabetes are urgent tasks. 


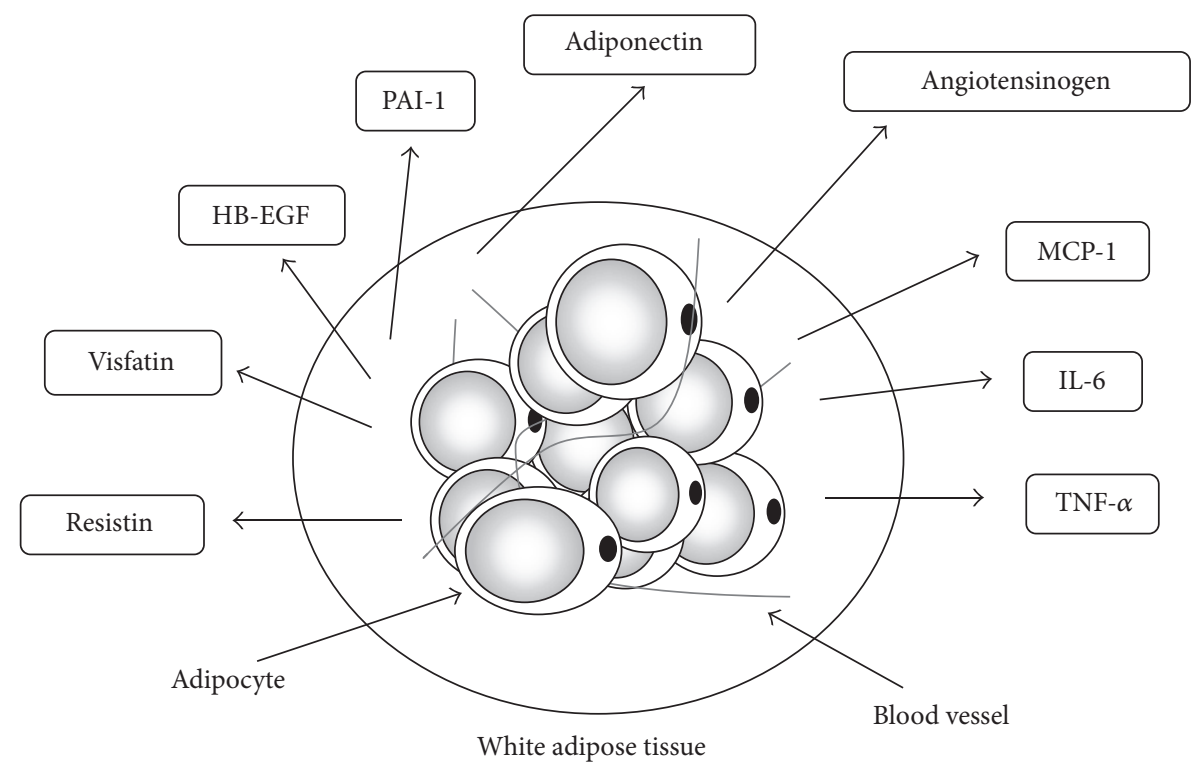

FIGURE 1: Various adipokines are secreted by white adipose tissue. White adipose tissue (WAT) secretes various humoral factors called adipokines: TNF- $\alpha$, tumor necrosis factor- $\alpha$; MCP-1, monocyte chemoattractant protein-1; IL-6, interleukin-6; HB-EGF, heparin-binding epidermal growth factor-like growth factor; and, PAI-1, plasminogen activator inhibitor-1. Adipokines are actively involved in metabolic reactions.

While white adipose tissue (WAT) was previously thought to be merely a matter of energy storage, recent examination at the molecular level has shown that adipocyte secretes various biologically active substances collectively known as "adipokines" (Figure 1) and that dysregulation of the expression of adipokines due to obesity is closely associated with the development of insulin resistance, which is a clinical condition of type 2 diabetes [7-9]. Therefore, WAT is thought to be one of the tissues that cause lifestyle-related diseases, and this has attached importance to both decreasing WAT mass and improving the disordered secretion of adipokines as strategies toward the prevention and improvement of lifestyle-related disease. It has become clear that oxidative stress is deeply involved in the dysfunction that includes the expression disorder of adipokines in WAT due to obesity [10-13]. On the other hand, exercise training (TR) not only decreases WAT mass but also affects the expression of various adipokines in WAT $[14,15]$. Moreover, TR is now reported to affect the oxidative stress in WAT. This review outlines the mechanisms for the dysregulated expression of adipokines due to increases in oxidative stress in WAT and also reviews the effect of TR, which is a useful strategy for the prevention and improvement of obesity and type 2 diabetes.

\section{Inflammatory Changes in WAT and Adipokines}

Obesity is a major cause of insulin resistance which is one of the type 2 diabetic clinical conditions. Recent studies have defined the role that chronic and mild systemic inflammation plays in the development of diabetic conditions. In fact, a rise in inflammatory markers such as C-reactive protein (CRP), haptoglobin, and fibrinogen in the blood is recognized in diabetic patients, and increases in interleukin- (IL-) $1 \beta$, IL-6, and CRP in the blood are predictive factors for type 2 diabetes [16-20]. Moreover, the blood concentration of macrophage migration inhibitory factor (MIF), which is a humoral factor that controls the migration of macrophage, in type 2 diabetic patients has been reported to be higher than that of healthy persons [21]. Furthermore, the blood levels of monocyte chemoattractant protein-1 (MCP-1), which is identified as a monocyte chemotactic factor, also rise in obese individuals [22]. On the other hand, a great deal of evidence shows that hypertrophic WAT itself shows inflammatory change [7-9]. When WAT is enlarged due to surplus energy intake or lack of physical exercise, an infiltration of macrophage, neutrophils, and T-cells is observed in WAT. In WAT infiltrated by macrophages, the production of proinflammatory adipokines, such as tumor necrosis factor- $\alpha$ (TNF- $\alpha$ ) and MCP-1, is increased and the production of anti-inflammatory adiponectin is decreased, and then a chronic inflammatory condition develops (Figure 2). Increases in proinflammatory adipokines act not only on adipocytes but also on paracrine, skeletal muscle, and liver, bringing about insulin resistance in those organs [23-25].

\section{Representative Adipokines and Their Functions}

3.1. TNF- $\alpha$. There are a number of reports that focus on typical inflammatory adipokine TNF- $\alpha$ and its involvement in insulin resistance and other actions since the expression of TNF- $\alpha$ was found to be upregulated in the WAT of obese model animals $[26,27]$. The expression of TNF- $\alpha$ increases in the WAT of obese animals as well as that of human WAT due to obesity, and the expression level of TNF- $\alpha$ in WAT shows a 




Figure 2: Model of the generation of oxidative stress and the development of chronic inflammation in obese WAT. Adipocytes begin to grow as a result of factors such as excess energy intake and lack of exercise, and macrophages infiltrate into WAT. Moreover, the expressions of NADPH oxidase subunits increase and those of antioxidants, such as superoxide dismutase (SOD), glutathione peroxidase (GPx), and catalase, decrease. As a result, reactive oxygen species (ROS) are produced in excess. Oxidative stress in obese WAT relates to dysregulated expression of inflammation-related adipokines via the activation of nuclear factor- $\kappa \mathrm{B}$ (NF- $\kappa \mathrm{B}$ ) and mitogen-activated protein kinase (MAPK). The dysregulated expression of adipokines induces inflammation of WAT, contributing to the development of insulin resistance.

significant positive correlation with body mass index (BMI) and blood insulin concentration [28-30]. TNF- $\alpha$ attenuates insulin signaling via the insulin receptor substrate 1- (IRS1-) mediated inhibition of insulin receptor tyrosine kinase activity in areas such as skeletal muscle, and it reduces the expression of glucose transporter (GLUT) 4 and adiponectin in adipocytes [31-34]. Therefore, increased TNF- $\alpha$ causes the development of insulin resistance in skeletal muscle and WAT. On the other hand, while a TNF- $\alpha$ knockout mouse showed the same level of obesity as a control mouse by means of a high fat diet (HFD) feeding, insulin resistance was not shown, and the GLUT4 protein contents in skeletal muscle increased [35]. Furthermore, tyrosine phosphorylation of an insulin receptor by insulin stimuli in visceral WAT and skeletal muscle was accelerated. Also, insulin resistance is shown to be weak in obese TNF- $\alpha$ receptor knockout mice [36]. Nevertheless, different reports coexist concerning the role of TNF- $\alpha$ in the cause of insulin resistance at the molecular level, which arises from actual cases where TNF$\alpha$ in the blood was blocked. When glucose metabolism has improved, however, some studies have failed to demonstrate the beneficial effects on glucose metabolism caused by the blockage of TNF- $\alpha$ in the blood [37-42]. Therefore, further prospective studies are required.

3.2. $M C P-1$. Increases in the genetic manifestations of MCP1 have been found in the WAT of obese mice [43, 44]. Also, a positive correlation has been established with the degree of obesity and the blood concentration of MCP-1, which induces the infiltration of macrophage into WAT via $\mathrm{C}-\mathrm{C}$ chemokine receptor-2 (CCR2) and also plays a role in inflammatory changes $[22,45]$. A mouse genetically modified for an enhanced expression of MCP-1 in adipocytes showed no differences in body mass, WAT mass, or the size of adipocytes compared with a control mouse, but the infiltration of macrophage into WAT was increased by comparison and an enhanced expression of TNF- $\alpha$ in WAT was observed [43]. Therefore, the infiltration of macrophage into WAT due to an increased MCP-1 signal was suggested to cause further production of inflammatory adipokines such as TNF$\alpha$. As a result of that study, the inflammatory response in WAT is thought to be an amplifier of these processes. Moreover, tyrosine phosphorylation of IRS-1 and phosphorylation of Akt, which are essential intermediate factors in insulin signaling, was reduced in the WAT of mice that were genetically modified to express only MCP-1 excessively in adipocytes [43]. In another study, when a MCP-1 knockout mouse was fed a HFD to the point of obesity, the infiltration of macrophage into WAT was controlled and insulin sensitively was increased in a more sensitive manner compared with that in a control mouse [44]. Another study found that, in CCR2 knockout mouse, infiltration of macrophage in WAT due to HFD feeding-induced obesity was reduced and insulin sensitively was enhanced by comparison with wild type mice [45]. CCR2 manifests itself in monocytes and macrophages as well as in adipocytes and skeletal muscle cells, and MCP-1 is suggested to directly act on those cells to attenuate the insulin signal [43]. 
3.3. Adiponectin. Adiponectin increases fatty acid oxidation and glucose uptake in skeletal muscle, and in the liver it exerts the inhibitory effect of gluconeogenesis [46, 47]. Adiponectin also inhibits the expression and secretion of TNF- $\alpha$ in macrophage and increases the production of antiinflammatory cytokines, such as IL-10, while controlling the attachment of monocytes to vascular endothelial cells and the transformation of macrophage into foam cells $[48,49]$. Thus, adiponectin is thought to have anti-inflammatory effects. In accordance with that function, the expression of gene for adiponectin is reduced in the WAT of genetically obese mice and obese humans, and both obese individuals and diabetic patients have a lower blood concentration of adiponectin compared with healthy individuals [50, 51]. Additionally, there is a negative correlation between the blood concentration of adiponectin and the degree of insulin resistance [52]. When a physiological concentration of adiponectin is administered to KKAy mice (model mice for type 2 diabetes), insulin resistance and hyperlipidemia are improved. On the other hand, adiponectin or its receptor (AdipoR) knockout mice has exhibited insulin resistance [46, 47]. These finding suggests that a decrease in adiponectin expression in WAT is closely associated with the cause of insulin resistance and the onset of type 2 diabetes. Also, adiponectin is suggested to be involved in mitochondrial biogenesis since a knockout mouse of AdipoR in skeletal muscle showed a reduced mitochondrial content, reduced type I muscle fibers, and decreased capacity for exercise [53]. A recent report stated that the oral administration of AdipoR agonist (AdipoRON) improved insulin resistance and glucose tolerance in a diabetic mouse, and clinical applications are expected $[54,55]$.

3.4. Leptin. Leptin is a hormone that is secreted from adipocytes, and leptin receptors (ob-R) that lay on the hypothalamus produce a strong suppression of feeding, a rise in energy consumption, and improvements in glycometabolism [5658]. Although leptin gene expression is enhanced in the WAT of obese individuals and the blood concentration increases in obese individuals as well as in obese animals, the effects of a suppression of feeding and a rise in energy consumption are hampered by the appearance of a dysfunction of leptin that is referred to as "leptin resistance" [57, 59-61]. Therefore, obesity is not improved efficiently even though leptin concentration in the blood is high. On the other hand, it is suggested that leptin is related to immune reactions. In fact, thymic atrophy and immunodeficiency have been observed in leptin-deficient (ob/ob) mice and also in ob-Rdeficient (db/db) mice [62]. Moreover, leptin is known to have an inflammatory function. Leptin increases inflammatory cytokines such as TNF- $\alpha$ and stimulates macrophages in mice to induce the production of chemokines [63-65]. Recently, leptin was suggested to be involved in a phenotype of infiltrated macrophages in the WAT of obese and diabetic mice [66].

3.5. IL-6. IL-6 is produced in various types of cells, such as adipocytes, lymphocytes, and macrophages, and is involved in functions such as immune responses and inflammation
[67-69]. Furthermore, IL-6 acts on liver to increase production of the inflammation biomarker CRP [70-73]. Therefore, IL-6 is suggested to be deeply involved in the onset of autoimmune disease. The aberrational production of IL- 6 is thought to be a cause of articular rheumatism [74]. IL6 may be involved in the cause of insulin resistance since its blood concentration is high in obese individuals and in type 2 diabetic patients, and expression of the IL- 6 gene is increased in the subcutaneous WAT of individuals with insulin resistance [75-77]. When IL-6 is added to adipocytes, the tyrosine phosphorylation of IRS-1 that is stimulated by insulin is weakened and glucose uptake into cells is attenuated due to a decrease in GLUT4 [78].

\section{Overproduction of ROS in WAT due to Obesity}

Obesity has been associated with systemic oxidative stress, and clinical studies have shown that the onset of metabolic syndrome and type 2 diabetes is involved in systemic oxidative stress [11, 12, 79, 80]. For instance, highly sensitive CRP and other oxidative stress markers, such as oxidized low-density lipoprotein, are high in obese individuals, and positive correlations with these oxidative stress markers and BMI and percent body fat have been observed [81]. Moreover, in type 2 diabetic patients, lipids, protein, and DNA oxidation are recognized in the blood, and a positive correlation has been noted between the degree of oxidation and glycemic control [13]. On the other hand, increased oxidative stress has been described in the WAT of obese animals. Enlarged adipocytes are a significant source of ROS and excessively produced ROS is deeply involved in the dysfunction of WAT, which includes insulin resistance and inflammatory reactions (Figure 2) [82]. In KKAy mice, elevated lipid oxidation and the generation of $\mathrm{H}_{2} \mathrm{O}_{2}$ are observed in WAT but neither in liver nor in skeletal muscles, and increases in oxidative stress have also been observed in the WAT of HFD and ob/ob mice [82-84].

ROS is believed to have different sources in WAT. The first ROS source is mitochondria. A mitochondrion is the main energy-producing organ and is also responsible for the generation of oxidative stress. During the process of energy production in mitochondria by oxidative phosphorylation, a portion of the oxygen molecule creates a superoxide. Therefore, an influx of excess nutrients to adipocytes is thought to bring about increases in the mitochondrial substrate load, which results in enhanced production of ROS in mitochondria [11]. In fact, highly concentrated glucose and the exposure of free fatty acids (FFA) increase ROS generation in mitochondria in 3T3-L1 adipocytes [85-87]. Also, oxidative stress in WAT is elevated when mice become hyperglycemic [88]. Additionally, it is understandable that enhanced oxidative stress in WAT induces mitochondrial dysfunction, which causes further increases in oxidative stress in WAT [89]. Nevertheless, some reports argue that FFA added to adipocytes is transformed into acyl-CoA without significant mitochondrial oxidation and that oxidative phosphorylation or beta-oxidation does not elevate when glucose and palmitic acid are added to adipocytes [90, 91]. Therefore, 
elucidation of the role that mitochondria plays in increasing ROS generation in WAT will require further study.

The second ROS source is due to NAPDH oxidase, which consists of seven member proteins (NOX1-5, DUOX1, and DUOX2), and is a major source of ROS production in various cells $[92,93]$. Nox produces superoxide when it receives an electron from the NADPH of the cytoplasm and transfers it to oxygen. Once it is produced, superoxide is further transformed into $\mathrm{H}_{2} \mathrm{O}_{2}$. NAPDH oxidase is a source of ROS in adipocytes, and NOX4 is particularly essential for ROS generation in adipocytes [94, 95]. In fact, ROS generation from the stimulus of glucose and palmitic acid is decreased in adipocytes where NOX4 expression is reduced [91]. Moreover, the fact that mitochondrion causes ROS and is a target for ROS production by NAPDH oxidase suggests that there is cross talk between mitochondria and NAPDH oxidase. NADPH oxidase has been associated with an elevation of ROS generation in obese WAT. The WAT of obese mice has demonstrated increased expressions of NADPH oxidase subunits and decreases in antioxidants such as superoxide dismutase (SOD) and glutathione peroxidase, which led to lipid peroxidation and an elevation in $\mathrm{H}_{2} \mathrm{O}_{2}$ production (Figure 2) [84].

\section{Dysregulated Production of Adipokines in WAT due to Oxidative Stress}

Obesity-induced increase in oxidative stress in WAT is suggested to be one of the causes of the dysregulated expression of inflammatory-related adipokines (Figure 2). The enhanced expression of genes for inflammatory adipokines such as TNF- $\alpha$ and the decrease in anti-inflammatory adiponectin gene expression are seen in the WAT of KKAy mice, which is accompanied by high levels of oxidative stress [84]. Also, when an oxidant is directly added to cultured 3T3L1 adipocytes, the expressions of the IL- 6 and MCP-1 genes increase and that of adiponectin decreases [96, 97]. On the contrary, antioxidant treatment for adipocytes, such as polyphenol addition, definitely attenuates the expression of genes for TNF- $\alpha$ and MCP-1 in adipocytes [98, 99]. Members of the mitogen-activated protein kinase (MAPK) family, such as extracellular signal-regulated kinase (ERK) and cJun N-terminal kinase (JNK) and transcription factor nuclear factor- $\kappa \mathrm{B}(\mathrm{NF}-\kappa \mathrm{B})$, are activated by oxidative stress and significant mediators of oxidative stress-induced intracellular signal transduction, and they are thought to play a significant role in the dysregulated expression of adipokines due to oxidative stress (Figure 2) [100,101]. Oxidative stress activates $\mathrm{NF}-\kappa \mathrm{B}$ in various cells and controls the expressions of TNF$\alpha$ and MCP-1 [101-103]. Adding $N$-acetyl-cysteine (NAC), which is a strong antioxidant, weakens the activation of $\mathrm{NF}-\kappa \mathrm{B}$, and, as a result, the enhancement of plasminogen activator inhibitor-1 expression by TNF- $\alpha$ is attenuated [104]. On the other hand, ERK's activation is thought to be involved in the expression of MCP-1 in adipocytes [105]. Moreover, since a large number of inflammatory cytokines accelerate ROS generation in macrophage, monocytes, and vascular endothelial cells, inflammation-related cross talk between infiltrated macrophage and adipocytes is expected to be amplified in obese WAT.

\section{The Effect of TR on Preventing and Improving Obesity and Type 2 Diabetes and the Expression of Adipokines in WAT}

It is widely accepted that physical exercise is effective in preventing and improving obesity and lifestyle-related diseases. For instance, Helmrich et al. [106] tracked 5,990 graduates of Pennsylvania University for 14 years and reported that every $500 \mathrm{kcal}$ increase in the amount of exercise reduces the risk of the development of diabetes by $6 \%$. Also, according to a follow-up survey of 21,271 US male medical doctors, the risk of developing diabetes fell in the group that experienced exercise to the point of sweating at least once a week [107]. Moreover, Manson et al. [108] followed the progress of 87,253 US female nurses for 8 years and found that the relative risk of developing diabetes, for the group that exercised to the point of sweating at least once a week, dropped to 0.84 compared with the group that exercised less than once a week.

A large number of examinations as to effect of TR on the expression of adipokines in WAT and the blood level of adipokines have been conducted for both animal experiments and human studies. However, every report did not agree due to differences in experimental subjects, exercise intensity, or exercise duration [14]. For example, the enhanced expression of the gene for TNF- $\alpha$ in the mesenteric visceral WAT of HFD feeding-induced obese mice is reported to have been inhibited by spontaneous running exercise in a rotating cage over a period of 6 weeks [109]. Furthermore, in a similar report combining a HFD with treadmill running, there was no difference in TNF- $\alpha$ gene expression in the visceral WAT of mice between a HFD group that continued TR for 6 weeks and a group with a HFD alone. After further 6 weeks, however, the increased expression of the gene for TNF- $\alpha$ due to the HFD feeding was attenuated by TR [110]. We have also reported that TNF- $\alpha$ protein content in the visceral WAT of rats was decreased by making them run on treadmills for 9 weeks [111, 112]. Nevertheless, when mice are subjected to the combination of a high-sucrose diet and TR that consists of spontaneous running, increases in TNF- $\alpha$ genes and in protein expression are routinely observed in mesenteric visceral WAT by comparison with groups that have only a highsucrose diet [113]. Lira et al. [114] also observed an increased amount of TNF- $\alpha$ in the mesenteric visceral WAT of rats subjected to 8 weeks of treadmill TR. In examinations of obese people, Bruun et al. [115] have reported that when TR, such as walking five times a week, and dietary manipulation were adopted by highly obese male and female adults for 15 weeks, TNF- $\alpha$ gene expression in subcutaneous WAT decreased. Other reports, however, have found that TNF- $\alpha$ in human subcutaneous WAT was not changed due to TR $[116,117]$. Although the above-mentioned discrepancy about the effects of TR on the TNF- $\alpha$ expression in WAT could not be resolved at this time, one of the possible reasons for the discrepancy may be site differences in WAT because TR 
tends to attenuate the TNF- $\alpha$ expressions in the epididymal and retroperitoneal WAT but to increase mesenteric WAT [111-114, 116, 117]. Moreover, TR appears to be insensitive to the TNF- $\alpha$ contents in the subcutaneous WAT. In our experiment, TR did not affect the TNF- $\alpha$ protein content in the subcutaneous WAT of the rats, although the TNF$\alpha$ protein expressions in the epididymal and retroperitoneal WAT were decreased by TR [111]. Adipokines have been reported to exhibit fat depot-specific expression [118]. For example, the TNF- $\alpha$ level in the mesenteric WAT is suggested to be higher than those in the omental and subcutaneous WAT [118-120]. Therefore, TR may induce fat depot-specific differences in adipokine expression. Besides adipokines, the adaptation of basal autophagic activity following TR has been reported recently to exhibit fat depot-specific differences [121]. On the other hand, there have been indications that obesity-induced increases in TNF- $\alpha$ levels in WAT are not due to adipocytes but rather to increased expression by infiltrating macrophages, based on an experiment that cocultured adipocyte and macrophage cell lines [122]. As Harman-Boehm et al. [123] reported that CD68-positive macrophages are more highly abundant in omental than in subcutaneous WAT in lean and obese subjects, differences in the number of infiltrating macrophages in each WAT are speculated to reflect the effects of TR on TNF- $\alpha$ expression. Similar to TNF- $\alpha$, conflicting results have been obtained with regard to MCP-1. Expression of the MCP-1 gene increases in the visceral WAT of a mouse fed HFD, and this increased expression is attenuated by spontaneous running for 6 weeks [109]. Other examinations that have combined HFD feeding and TR that involved running on a treadmill have shown that MCP-1 gene expression, which normally increases due to HFD feeding, was decreased [110]. We also observed that MCP-1 protein contents in rat visceral WAT were reduced by 9 weeks of TR that involved running on a treadmill [111]. However, expression of the gene for MCP-1 was not altered in either the subcutaneous or visceral WAT of a rat engaged in spontaneous running TR for 4 weeks, and the same was true for obese individuals engaged in aerobic exercise for 12 weeks $[116,124]$. Meanwhile, increased expression of the gene for adiponectin was observed in the subcutaneous WAT of obese individuals who underwent a combination of dietary therapy and TR such as walking 5 times a week for 15 weeks or endurance training for 12 weeks $[115,116,125]$ Nevertheless, when obese women engaged in TR for 12 weeks a decrease in body fat was observed, but no effect was seen on adiponectin gene expression in subcutaneous WAT [117]. Examinations using rats have shown that the expression of genes for adiponectin in visceral and subcutaneous adipocytes was upregulated by means of TR that involved 9 weeks of running on a treadmill [126]. However, Gollisch et al. [124] have indicated that short-term (4 weeks) TR by self-propelled running inhibits HFD-induced upregulation of the gene expression of adiponectin in the subcutaneous WAT of rats. Interestingly, in this study, no effect of TR on the expression of the gene for adiponectin in visceral WAT was observed. Secretion and mRNA expression of adiponectin positively correlated with the size of isolated adipocytes in humans and rats [126, 127]. Nevertheless, the adiponectin expression levels in the WAT of genetically obese mice and obese humans are reduced $[50,51]$. Therefore, reduced adiponectin expression in vivo, rather than increases in adipocyte size, is speculated to be the result of inflammatory adipokines such as TNF- $\alpha$ [128]. In fact, the TR upregulated expression of the gene for adiponectin in the subcutaneous WAT has been reported in obese humans with downregulation of TNF- $\alpha$ gene expression [115]. In the experiment about the early phase of obesity (4 weeks) by Gollisch et al. [124], the subcutaneous WAT mass was increased and the adipocyte number per gram of WAT tended to increase, but the inflammatory state in WAT was weak. Therefore, the effect of WAT expansion may be related to the enhancement of the adiponectin expression in subcutaneous WAT and TR appears to be able to inhibit the enhancement of adiponectin expression because TR attenuates increases in subcutaneous WAT due to HFD feeding.

\section{The Effect of TR on Oxidative Stress in WAT}

The size of adipocytes greatly affects the expression of adipokines [127-130]. For example, in isolated human adipocytes, secretion levels of TNF- $\alpha$, MCP-1, and IL- 6 are positively correlated with cell size, and after correction for the cell surface area, there remains a significant difference between very large and small adipocytes for MCP-1 and IL-6 [129]. TR is well known to decrease WAT mass (size of adipocytes), and, therefore, it is understandable that the effect of TR on the dysregulated expression of adipokines in WAT largely depends on a decrease in adipocyte size. On the other hand, it seems that one of the unique effects of TR other than the reduction of WAT mass is to decrease oxidative stress in WAT (Figure 3). For example, we found that the values for lipid peroxidation in the epididymal and retroperitoneal WATs of rats engaged in TR are lower than in those of control rats and that TNF- $\alpha$ and MCP-1 content in WAT are less in the TR groups than in control groups [111]. Also, the phosphorylation of ERK, which is activated by oxidative stress and is involved in the expression of MCP-1, was attenuated by TR $[105,111]$. Moreover, de Farias et al. [131] have also reported that the HFD feedinginduced increases in lipid peroxidation in mice WAT were significantly diminished by TR. The underlying mechanisms of the antioxidative effects of TR on WAT have been examined for an alternation of the NADPH oxidase and antioxidant enzymes. In our experiment mentioned above, the MnSOD content in WAT was increased due to TR, whereas NOX2 was reduced [111, 112]. Also, in examinations of obese mice, expression of the Mn-SOD gene was increased by TR and that of MCP-1 and NOX2 genes was decreased [132]. Additionally, when obese mice have been engaged in TR, enhanced enzymatic activity was observed for Mn-SOD and catalase [131]. Ferrara et al. [133] found that TR decreases oxidative stress with increases in Mn-SOD and catalase proteins in the WAT of old rats. However, at least one report has stated that even when conducted in combination with a HFD TR affects the gene expression of neither Mn-SOD nor NOX2, and, therefore, further examination is required [134].

There are many unclear points regarding whether the effect of TR is specific to the expressions of NADPH oxidase 


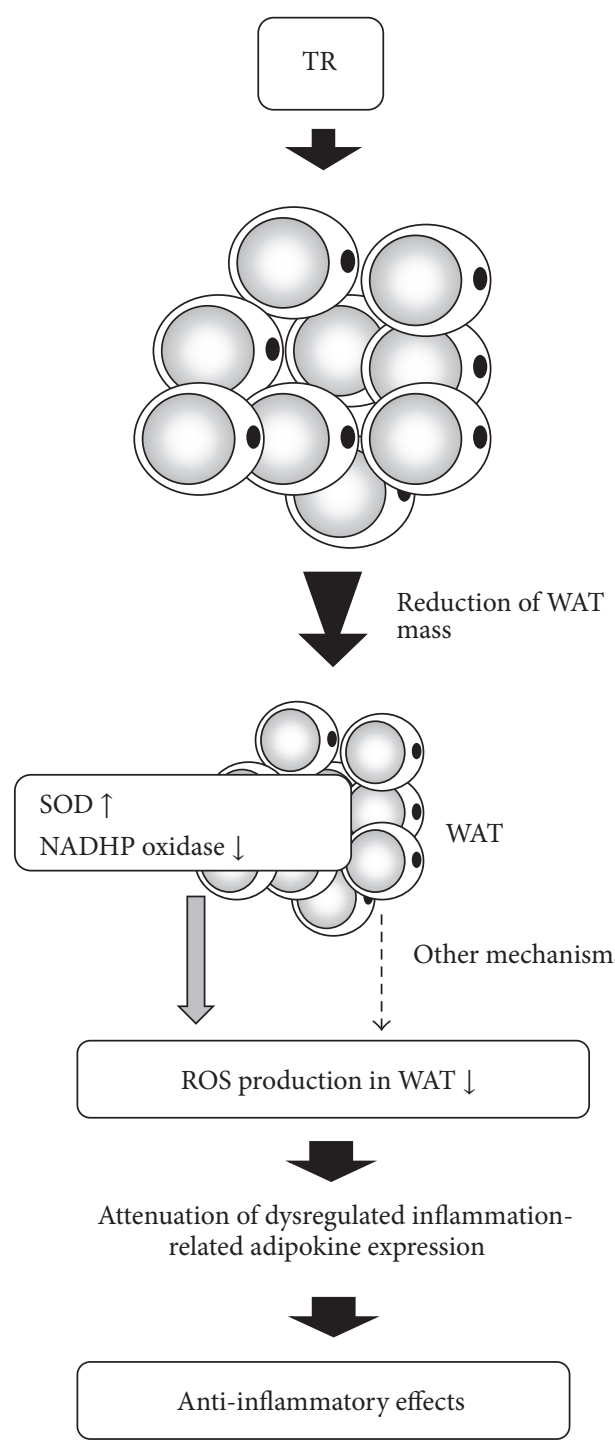

FIGURE 3: Schematic model for the antioxidative/anti-inflammatory effects of exercise training in WAT. Exercise training (TR) reduces WAT mass and attenuates an enhanced expression of NADPH oxidase and a decreased expression of Mn-SOD. Therefore, TR is thought to decrease the expression of inflammation-related adipokines via a reduction in oxidative stress in WAT.

and antioxidant enzymes in WAT with the exception of decreases in WAT mass and whether the effects of hormesis by TR exist. As mentioned above, the expression of NADPH oxidase increases and that of antioxidant enzyme decreases in the WAT of obese mice, and, as a result, oxidative stress rises in WAT [84]. Moreover, as lipid droplets form, oxidative stress rises in 3T3-L1 adipocytes [84]. Since TR reduces WAT mass, it is possible that TR-induced decreases in the WAT mass cause changes in the expression of NADPH oxidase and antioxidant enzymes. On the other hand, many examinations have been conducted on the physical exerciseinduced hormesis effect in skeletal muscles. Physical exercise increases oxidative stress in skeletal muscle, and then physical exercise inducing oxidative stress upregulates the expression of antioxidant enzymes in skeletal muscle; in other words, antioxidant adaptation against oxidative stress is caused by the physical exercise of skeletal muscle [135-139]. Since the amount of oxygen consumed in exercising skeletal muscle increases beyond the amount at rest, ROS production in the mitochondria increases in exercising skeletal muscle as well $[136,139]$. Also, high-intensity physical exercise brings about cell damage in skeletal muscle, which leads to an infiltration of inflammatory cells such as neutrophils into inflammatory sites in skeletal muscle, resulting in the development of ROS due to NADPH oxidase and myeloperoxidase [135]. Exercise-induced oxidative stress in muscles directly causes muscle damage by oxidation of cell components such as lipids, proteins, and DNA, suggesting to contribute to muscle fatigue, muscle soreness, and exercise-induced muscle injury [140-142]. Many animal studies indicate that ROS is a contributor to contraction-induced muscle fatigue during prolonged endurance exercise, and administration of antioxidants such as NAC is reported to delay muscle fatigue in human subjects [142]. Similarly, several numbers of human studies suggest that supplementation with antioxidant brings about treatment effectiveness to highintensity exercise-induced muscle damage [143]. In addition, ROS produced during exercise may be involved in delayedonset muscle damage related to inflammation. For example, oxidative stress and the expressions of proteins for cytokineinduced neutrophil chemoattractant 1 and MCP-1 in rat gastrocnemius significantly increased at $24 \mathrm{~h}$ after running exercise, and these increases were significantly ameliorated by supplementation with antioxidant $\alpha$-tocopherol [144]. Meanwhile, it is suggested that increased oxidative stress activates NF- $\kappa \mathrm{B}$, and, as a result, activated NF- $\kappa \mathrm{B}$ upregulates the expression of antioxidant enzymes such as Mn-SOD in skeletal muscle $[137,138]$. Furthermore, the activity of elevated SOD in skeletal muscle has shown a dependence on the intensity of physical exercise [145-147]. While increases in oxidative stress are observed in not only skeletal muscle but also the liver, heart, and lungs of rats during a maximum single bout of exercise, it is unknown whether oxidative stress in WAT is increased [148]. It is accepted that oxidative stress in the blood increases due to high-intensity physical exercise, and exercise intensity must be relatively high during an examination where the expression of Mn-SOD in WAT increases in animal experiments [111, 112, 132]. Therefore, it is possible that blood oxidative stress leads to an increase in Mn-SOD expression. Other reports, however, have pointed out that when adipocytes are exposed to oxidative stress in vitro, the expression of NADPH oxidase rises; thus further consideration is required [83].

\section{Conclusions}

Reducing oxidative stress in WAT is thought to be essential as a strategy for the prevention and improvement of lifestylerelated diseases, since recent evidence has shown that an increase in oxidative stress is closely related to the dysfunction of WAT due to a dysregulated expression of adipokines. TR is thought to be an important tool for preventing and improving obesity and lifestyle-related diseases, and it is 
possible that TR attenuates the dysregulated expression of adipokines by reducing the oxidative stress in WAT. However, many points remain unclear and further research is warranted.

\section{Competing Interests}

The authors declare that there is no conflict of interests regarding the publication of this paper.

\section{Acknowledgments}

This work was partially supported by grants-in-aid for Specific Project Research from the Ministry of Education, Culture, Sport, Science, and Technology of Japan.

\section{References}

[1] S. Rössner, "Obesity: the disease of the twenty-first century," International Journal of Obesity and Related Metabolic Disorders, vol. 26, pp. S2-S4, 2002.

[2] NCD Risk Factor Collaboration (NCD-RisC), "Trends in adult body-mass index in 200 countries from 1975 to 2014: a pooled analysis of 1698 population-based measurement studies with 19.2 million participants," The Lancet, vol. 387, no. 10026, pp. 1377-1396, 2016.

[3] L. J. Aronne, "Epidemiology, morbidity, and treatment of overweight and obesity," Journal of Clinical Psychiatry, vol. 62, supplement 23, pp. 13-22, 2001.

[4] R. T. Jung, "Obesity as a disease," British Medical Bulletin, vol. 53, no. 2, pp. 307-321, 1997.

[5] NCD Risk Factor Collaboration (NCD-RisC), "Worldwide trends in diabetes since 1980: a pooled analysis of 751 population-based studies with 4.4 million participants," The Lancet, vol. 387, no. 10027, pp. 1513-1530, 2016.

[6] E. A. Finkelstein, J. G. Trogdon, J. W. Cohen, and W. Dietz, "Annual medical spending attributable to obesity: payer- and service-specific estimates," Health Affairs, vol. 28, no. 5, pp. w822-w831, 2009.

[7] C. N. Lumeng and A. R. Saltiel, "Inflammatory links between obesity and metabolic disease," The Journal of Clinical Investigation, vol. 121, no. 6, pp. 2111-2117, 2011.

[8] H. Tilg and A. R. Moschen, "Adipocytokines: mediators linking adipose tissue, inflammation and immunity," Nature Reviews Immunology, vol. 6, no. 10, pp. 772-783, 2006.

[9] K. Rabe, M. Lehrke, K. G. Parhofer, and U. C. Broedl, "Adipokines and insulin resistance," Molecular Medicine, vol. 14, no. 11-12, pp. 741-751, 2008.

[10] A. Fernández-Sánchez, E. Madrigal-Santillán, M. Bautista et al., "Inflammation, oxidative stress, and obesity," International Journal of Molecular Sciences, vol. 12, no. 5, pp. 3117-3132, 2011.

[11] S. Le Lay, G. Simard, M. C. Martinez, and R. Andriantsitohaina, "Oxidative stress and metabolic pathologies: from an adipocentric point of view," Oxidative Medicine and Cellular Longevity, vol. 2014, Article ID 908539, 18 pages, 2014.

[12] L. Marseglia, S. Manti, G. D’Angelo et al., "Oxidative stress in obesity: a critical component in human diseases," International Journal of Molecular Sciences, vol. 16, no. 1, pp. 378-400, 2015.

[13] C. K. Roberts and K. K. Sindhu, "Oxidative stress and metabolic syndrome,” Life Sciences, vol. 84, no. 21-22, pp. 705-712, 2009.
[14] T. Sakurai, J. Ogasawara, T. Kizaki et al., "The effects of exercise training on obesity-induced dysregulated expression of adipokines in white adipose tissue," International Journal of Endocrinology, vol. 2013, Article ID 801743, 28 pages, 2013.

[15] T. Sakurai, J. Ogasawara, T. Kizaki et al., "Preventive and improvement effects of exercise training and supplement intake in white adipose tissues on obesity and lifestyle-related diseases," Environmental Health and Preventive Medicine, vol. 17, no. 5, pp. 348-356, 2012.

[16] M. Y. Donath and S. E. Shoelson, "Type 2 diabetes as an inflammatory disease," Nature Reviews Immunology, vol. 11, no. 2, pp. 98-107, 2011.

[17] C. Herder, T. Illig, W. Rathmann et al., "Inflammation and type 2 diabetes: results from KORA Augsburg," Gesundheitswesen, vol. 67, no. 1, pp. S115-S121, 2005.

[18] J. C. Pickup, M. B. Mattock, G. D. Chusney, and D. Burt, "NIDDM as a disease of the innate immune system: association of acute-phase reactants and interleukin-6 with metabolic syndrome X," Diabetologia, vol. 40, no. 11, pp. 1286-1292, 1997.

[19] A. D. Pradhan, J. E. Manson, N. Rifai, J. E. Buring, and P. M. Ridker, "C-reactive protein, interleukin 6, and risk of developing type 2 diabetes mellitus," The Journal of the American Medical Association, vol. 286, no. 3, pp. 327-334, 2001.

[20] J. Spranger, A. Kroke, M. Möhlig et al., "Inflammatory cytokines and the risk to develop type 2 diabetes: results of the prospective population-based European Prospective Investigation into Cancer and Nutrition (EPIC)-Potsdam study," Diabetes, vol. 52, no. 3, pp. 812-817, 2003.

[21] Y. I. Sánchez-Zamora and M. Rodriguez-Sosa, "The role of MIF in type 1 and type 2 diabetes mellitus," Journal of Diabetes Research, vol. 2014, Article ID 804519, 6 pages, 2014.

[22] C. S. Kim, H. S. Park, T. Kawada et al., "Circulating levels of MCP-1 and IL-8 are elevated in human obese subjects and associated with obesity-related parameters," International Journal of Obesity, vol. 30, no. 9, pp. 1347-1355, 2006.

[23] G. Fantuzzi, "Adipose tissue, adipokines, and inflammation," Journal of Allergy and Clinical Immunology, vol. 115, no. 5, pp. 911-919, 2005.

[24] S. P. Weisberg, D. McCann, M. Desai, M. Rosenbaum, R. L. Leibel, and A. W. Ferrante Jr., "Obesity is associated with macrophage accumulation in adipose tissue," The Journal of Clinical Investigation, vol. 112, no. 12, pp. 1796-1808, 2003.

[25] H. Xu, G. T. Barnes, Q. Yang et al., "Chronic inflammation in fat plays a crucial role in the development of obesity-related insulin resistance," The Journal of Clinical Investigation, vol. 112, no. 12, pp. 1821-1830, 2003.

[26] W. P. Cawthorn and J. K. Sethi, “TNF- $\alpha$ and adipocyte biology," FEBS Letters, vol. 582, no. 1, pp. 117-131, 2008.

[27] C. Qi and P. H. Pekala, "Tumor necrosis factor- $\alpha$-induced insulin resistance in adipocytes," Proceedings of the Society for Experimental Biology and Medicine, vol. 223, no. 2, pp. 128-135, 2000.

[28] G. S. Hotamisligil, P. Arner, J. F. Caro, R. L. Atkinson, and B. M. Spiegelman, "Increased adipose tissue expression of tumor necrosis factor- $\alpha$ in human obesity and insulin resistance," The Journal of Clinical Investigation, vol. 95, no. 5, pp. 2409-2415, 1995.

[29] G. S. Hotamisligil, N. S. Shargill, and B. M. Spiegelman, "Adipose expression of tumor necrosis factor- $\alpha$ : direct role in obesity-linked insulin resistance," Science, vol. 259, no. 5091, pp. 87-91, 1993. 
[30] P. A. Kern, M. Saghizadeh, J. M. Ong, R. J. Bosch, R. Deem, and R. B. Simsolo, "The expression of tumor necrosis factor in human adipose tissue. Regulation by obesity, weight loss, and relationship to lipoprotein lipase," The Journal of Clinical Investigation, vol. 95, no. 5, pp. 2111-2119, 1995.

[31] M. Fasshauer, J. Klein, S. Neumann, M. Eszlinger, and R. Paschke, "Hormonal regulation of adiponectin gene expression in 3T3-L1 adipocytes," Biochemical and Biophysical Research Communications, vol. 290, no. 3, pp. 1084-1089, 2002.

[32] G. S. Hotamisligil, A. Budavari, D. Murray, and B. M. Spiegelman, "Reduced tyrosine kinase activity of the insulin receptor in obesity-diabetes. Central role of tumor necrosis factor- $\alpha$," The Journal of Clinical Investigation, vol. 94, no. 4, pp. 1543-1549, 1994.

[33] G. S. Hotamisligil, D. L. Murray, L. N. Choy, and B. M. Spiegelman, "Tumor necrosis factor $\alpha$ inhibits signaling from the insulin receptor," Proceedings of the National Academy of Sciences of the United States of America, vol. 91, no. 11, pp. 48544858, 1994.

[34] J. M. Stephens and P. H. Pekala, "Transcriptional repression of the GLUT4 and C/EBP genes in 3T3-L1 adipocytes by tumor necrosis factor- $\alpha$," The Journal of Biological Chemistry, vol. 266, no. 32, pp. 21839-21845, 1991.

[35] K. T. Uysal, S. M. Wiesbrock, M. W. Marino, and G. S. Hotamisligil, "Protection from obesity-induced insulin resistance in mice lacking TNF- $\alpha$ function," Nature, vol. 389, no. 6651, pp. 610-614, 1997.

[36] K. T. Uysal, S. M. Wiesbrock, and G. S. Hotamisligil, "Functional analysis of tumor necrosis factor (TNF) receptors in TNF- $\alpha$ mediated insulin resistance in genetic obesity," Endocrinology, vol. 139, no. 12, pp. 4832-4838, 1998.

[37] H. Dominguez, H. Storgaard, C. Rask-Madsen et al., "Metabolic and vascular effects of tumor necrosis factor- $\alpha$ blockade with etanercept in obese patients with type 2 diabetes," Journal of Vascular Research, vol. 42, no. 6, pp. 517-525, 2005.

[38] J. Lo, L. E. Bernstein, B. Canavan et al., "Effects of TNF- $\alpha$ neutralization on adipocytokines and skeletal muscle adiposity in the metabolic syndrome," American Journal of PhysiologyEndocrinology and Metabolism, vol. 293, no. 1, pp. E102-E109, 2007.

[39] F. Ofei, S. Hurel, J. Newkirk, M. Sopwith, and R. Taylor, "Effects of an engineered human anti-TNF- $\alpha$ antibody (CDP571) on insulin sensitivity and glycemic control in patients with NIDDM," Diabetes, vol. 45, no. 7, pp. 881-885, 1996.

[40] T. L. Stanley, M. V. Zanni, S. Johnsen et al., “TNF- $\alpha$ antagonism with etanercept decreases glucose and increases the proportion of high molecular weight adiponectin in obese subjects with features of the metabolic syndrome," The Journal of Clinical Endocrinology \& Metabolism, vol. 96, no. 1, pp. E146-E150, 2011.

[41] B. Yazdani-Biuki, T. Mueller, H.-P. Brezinschek, J. Hermann, W. Graninger, and T. C. Wascher, "Relapse of diabetes after interruption of chronic administration of anti-tumor necrosis factor- $\alpha$ antibody infliximab: a case observation," Diabetes Care, vol. 29, no. 7, pp. 1712-1713, 2006.

[42] B. Yazdani-Biuki, H. Stelzl, H. P. Brezinschek et al., "Improvement of insulin sensitivity in insulin resistant subjects during prolonged treatment with the anti-TNF- $\alpha$ antibody infliximab," European Journal of Clinical Investigation, vol. 34, no. 9, pp. 641642, 2004.

[43] N. Kamei, K. Tobe, R. Suzuki et al., "Overexpression of monocyte chemoattractant protein-1 in adipose tissues causes macrophage recruitment and insulin resistance," The Journal of Biological Chemistry, vol. 281, no. 36, pp. 26602-26614, 2006.

[44] H. Kanda, S. Tateya, Y. Tamori et al., "MCP-1 contributes to macrophage infiltration into adipose tissue, insulin resistance, and hepatic steatosis in obesity," The Journal of Clinical Investigation, vol. 116, no. 6, pp. 1494-1505, 2006.

[45] S. P. Weisberg, D. Hunter, R. Huber et al., "CCR2 modulates inflammatory and metabolic effects of high-fat feeding," The Journal of Clinical Investigation, vol. 116, no. 1, pp. 115-124, 2006.

[46] T. Kadowaki and T. Yamauchi, "Adiponectin and adiponectin receptors," Endocrine Reviews, vol. 26, no. 3, pp. 439-451, 2005.

[47] T. Kadowaki, T. Yamauchi, N. Kubota, K. Hara, K. Ueki, and $\mathrm{K}$. Tobe, "Adiponectin and adiponectin receptors in insulin resistance, diabetes, and the metabolic syndrome," The Journal of Clinical Investigation, vol. 116, no. 7, pp. 1784-1792, 2006.

[48] R. Ouedraogo, Y. Gong, B. Berzins et al., "Adiponectin deficiency increases leukocyte-endothelium interactions via upregulation of endothelial cell adhesion molecules in vivo," The Journal of Clinical Investigation, vol. 117, no. 6, pp. 1718-1726, 2007.

[49] A. M. Wolf, D. Wolf, H. Rumpold, B. Enrich, and H. Tilg, "Adiponectin induces the anti-inflammatory cytokines IL-10 and IL-1RA in human leukocytes," Biochemical and Biophysical Research Communications, vol. 323, no. 2, pp. 630-635, 2004.

[50] Y. Arita, S. Kihara, N. Ouchi et al., "Paradoxical decrease of an adipose-specific protein, adiponectin, in obesity," Biochemical and Biophysical Research Communications, vol. 257, no. 1, pp. 79-83, 1999.

[51] E. Hu, P. Liang, and B. M. Spiegelman, "AdipoQ is a novel adipose-specific gene dysregulated in obesity," The Journal of Biological Chemistry, vol. 271, no. 18, pp. 10697-10703, 1996.

[52] C. Weyer, T. Funahashi, S. Tanaka et al., "Hypoadiponectinemia in obesity and type 2 diabetes: close association with insulin resistance and hyperinsulinemia," The Journal of Clinical Endocrinology \& Metabolism, vol. 86, no. 5, pp. 1930-1935, 2001.

[53] M. Iwabu, T. Yamauchi, M. Okada-Iwabu et al., "Adiponectin and AdipoR1 regulate PGC- $1 \alpha$ and mitochondria by $\mathrm{Ca}^{2+}$ and AMPK/SIRT1," Nature, vol. 464, no. 7293, pp. 1313-1319, 2010.

[54] M. Okada-Iwabu, T. Yamauchi, M. Iwabu et al., "A smallmolecule AdipoR agonist for type 2 diabetes and short life in obesity," Nature, vol. 503, no. 7477, pp. 493-499, 2013.

[55] Y. Zhang, J. Zhao, R. Li et al., "AdipoRon, the first orally active adiponectin receptor activator, attenuates postischemic myocardial apoptosis through both AMPK-mediated and AMPK-independent signalings," American Journal of Physiology-Endocrinology and Metabolism, vol. 309, no. 3, pp. E275-E282, 2015.

[56] J. L. Halaas, K. S. Gajiwala, M. Maffei et al., "Weight-reducing effects of the plasma protein encoded by the obese gene," Science, vol. 269, no. 5223, pp. 543-546, 1995.

[57] D. L. Morris and L. Rui, "Recent advances in understanding leptin signaling and leptin resistance," American Journal of Physiology-Endocrinology and Metabolism, vol. 297, no. 6, pp. E1247-E1259, 2009.

[58] A. Oswal and G. Yeo, "Leptin and the control of body weight: a review of its diverse central targets, signaling mechanisms, and role in the pathogenesis of obesity," Obesity, vol. 18, no. 2, pp. 221-229, 2010.

[59] R. V. Considine, M. K. Sinha, M. L. Heiman et al., "Serum immunoreactive-leptin concentrations in normal-weight and obese humans," The New England Journal of Medicine, vol. 334, no. 5, pp. 292-295, 1996. 
[60] F. Lönnqvist, P. Arner, L. Nordfors, and M. Schalling, "Overexpression of the obese $(\mathrm{ob})$ gene in adipose tissue of human obese subjects," Nature Medicine, vol. 1, no. 9, pp. 950-953, 1995.

[61] M. Maffei, J. Halaas, E. Ravussin et al., "Leptin levels in human and rodent: measurement of plasma leptin and ob RNA in obese and weight-reduced subjects," Nature Medicine, vol. 1, no. 11, pp. 1155-1161, 1995.

[62] J. K. Howard, G. M. Lord, G. Matarese et al., "Leptin protects mice from starvation-induced lymphoid atrophy and increases thymic cellularity in ob/ob mice," The Journal of Clinical Investigation, vol. 104, no. 8, pp. 1051-1059, 1999.

[63] N. Kiguchi, T. Maeda, Y. Kobayashi, Y. Fukazawa, and S. Kishioka, "Leptin enhances CC-chemokine ligand expression in cultured murine macrophage," Biochemical and Biophysical Research Communications, vol. 384, no. 3, pp. 311-315, 2009.

[64] J. Santos-Alvarez, R. Goberna, and V. Sánchez-Margalet, "Human leptin stimulates proliferation and activation of human circulating monocytes," Cellular Immunology, vol. 194, no. 1, pp. 6-11, 1999.

[65] H. Zarkesh-Esfahani, G. Pockley, R. A. Metcalfe et al., "Highdose leptin activates human leukocytes via receptor expression on monocytes," The Journal of Immunology, vol. 167, no. 8, pp. 4593-4599, 2001.

[66] S. C. Acedo, S. Gambero, F. G. P. Cunha, I. Lorand-Metze, and A. Gambero, "Participation of leptin in the determination of the macrophage phenotype: an additional role in adipocyte and macrophage crosstalk," In Vitro Cellular \& Developmental Biology-Animal, vol. 49, no. 6, pp. 473-478, 2013.

[67] T. Kishimoto, "Interleukin-6: from basic science to medicine40 Years in immunology," Annual Review of Immunology, vol. 23, pp. 1-21, 2005.

[68] T. Naka, N. Nishimoto, and T. Kishimoto, "The paradigm of IL6: from basic science to medicine," Arthritis Research, vol. 4, supplement 3, pp. S233-S242, 2002.

[69] A. M. W. Petersen and B. K. Pedersen, "The anti-inflammatory effect of exercise," Journal of Applied Physiology, vol. 98, no. 4, pp. 1154-1162, 2005.

[70] M. K. Ganapathi, D. Rzewnicki, D. Samols, S.-L. Jiang, and I. Kushner, "Effect of combinations of cytokines and hormones on synthesis of serum amyloid A and C-reactive protein in HEP 3B cells," The Journal of Immunology, vol. 147, no. 4, pp. 1261-1265, 1991.

[71] P. C. Heinrich, J. V. Castell, and T. Andus, "Interleukin-6 and the acute phase response," Biochemical Journal, vol. 265, no. 3 , pp. 621-636, 1990.

[72] H. Moshage, "Cytokines and the hepatic acute phase response," The Journal of Pathology, vol. 181, no. 3, pp. 257-266, 1997.

[73] J. E. Volanakis, "Human C-reactive protein: expression, structure, and function," Molecular Immunology, vol. 38, no. 2-3, pp. 189-197, 2001.

[74] K. Ishihara and T. Hirano, "IL-6 in autoimmune disease and chronic inflammatory proliferative disease," Cytokine \& Growth Factor Reviews, vol. 13, no. 4-5, pp. 357-368, 2002.

[75] J. R. Berggren, M. W. Hulver, and J. A. Houmard, "Fat as an endocrine organ: influence of exercise," Journal of Applied Physiology, vol. 99, no. 2, pp. 757-764, 2005.

[76] K. Eder, N. Baffy, A. Falus, and A. K. Fulop, "The major inflammatory mediator interleukin-6 and obesity," Inflammation Research, vol. 58, no. 11, pp. 727-736, 2009.

[77] S. Sindhu, R. Thomas, P. Shihab, D. Sriraman, K. Behbehani, and R. Ahmad, "Obesity is a positive modulator of IL-6R and IL-6 expression in the subcutaneous adipose tissue: significance for metabolic inflammation," PLoS ONE, vol. 10, no. 7, Article ID e0133494, 2015.

[78] C. Lagathu, J.-P. Bastard, M. Auclair, M. Maachi, J. Capeau, and M. Caron, "Chronic interleukin-6 (IL-6) treatment increased IL-6 secretion and induced insulin resistance in adipocyte: prevention by rosiglitazone," Biochemical and Biophysical Research Communications, vol. 311, no. 2, pp. 372-379, 2003.

[79] K. G. Alberti and P. Z. Zimmet, "Definition, diagnosis and classification of diabetes mellitus and its complications. Part 1: diagnosis and classification of diabetes mellitus provisional report of a WHO consultation," Diabetic Medicine, vol. 15, no. 7, pp. 539-553, 1998.

[80] W. Wonisch, A. Falk, I. Sundl, B. M. Winklhofer-Roob, and M. Lindschinger, "Oxidative stress increases continuously with BMI and age with unfavourable profiles in males," Aging Male, vol. 15, no. 3, pp. 159-165, 2012.

[81] E. Pihl, K. Zilmer, T. Kullisaar, C. Kairane, A. Mägi, and M. Zilmer, "Atherogenic inflammatory and oxidative stress markers in relation to overweight values in male former athletes," International Journal of Obesity, vol. 30, no. 1, pp. 141-146, 2006.

[82] N. Houstis, E. D. Rosen, and E. S. Lander, "Reactive oxygen species have a causal role in multiple forms of insulin resistance," Nature, vol. 440, no. 7086, pp. 944-948, 2006.

[83] J. M. Curtis, P. A. Grimsrud, W. S. Wright et al., "Downregulation of adipose glutathione S-tansferase A4 leads to increased protein carbonylation, oxidative stress, and mitochondrial dysfunction," Diabetes, vol. 59, no. 5, pp. 1132-1142, 2010.

[84] S. Furukawa, T. Fujita, M. Shimabukuro et al., "Increased oxidative stress in obesity and its impact on metabolic syndrome," The Journal of Clinical Investigation, vol. 114, no. 12, pp. 1752-1761, 2004.

[85] C.-L. Gao, C. Zhu, Y.-P. Zhao et al., "Mitochondrial dysfunction is induced by high levels of glucose and free fatty acids in 3T3L1 adipocytes," Molecular and Cellular Endocrinology, vol. 320, no. 1-2, pp. 25-33, 2010.

[86] H. Lee, Y. J. Lee, H. Choi, E. H. Ko, and J.-W. Kim, "Reactive oxygen species facilitate adipocyte differentiation by accelerating mitotic clonal expansion," The Journal of Biological Chemistry, vol. 284, no. 16, pp. 10601-10609, 2009.

[87] Y. Lin, A. H. Berg, P. Iyengar et al., "The hyperglycemiainduced inflammatory response in adipocytes: the role of reactive oxygen species," Journal of Biological Chemistry, vol. 280, no. 6, pp. 4617-4626, 2005.

[88] B. Lu, D. Ennis, R. Lai et al., "Enhanced sensitivity of insulinresistant adipocytes to vanadate is associated with oxidative stress and decreased reduction of vanadate $(+5)$ to vanadyl (+4)," Journal of Biological Chemistry, vol. 276, no. 38, pp. 35589-35598, 2001.

[89] C.-H. Wang, C.-C. Wang, H.-C. Huang, and Y.-H. Wei, "Mitochondrial dysfunction leads to impairment of insulin sensitivity and adiponectin secretion in adipocytes," FEBS Journal, vol. 280, no. 4, pp. 1039-1050, 2013.

[90] K. N. Frayn, D. Langin, and F. Karpe, "Fatty acid-induced mitochondrial uncoupling in adipocytes is not a promising target for treatment of insulin resistance unless adipocyte oxidative capacity is increased," Diabetologia, vol. 51, no. 3, pp. 394-397, 2008.

[91] C. Y. Han, T. Umemoto, M. Omer et al., "NADPH oxidasederived reactive oxygen species increases expression of monocyte chemotactic factor genes in cultured adipocytes," Journal of Biological Chemistry, vol. 287, no. 13, pp. 10379-10393, 2012. 
[92] K. Bedard and K.-H. Krause, "The NOX family of ROSgenerating NADPH oxidases: physiology and pathophysiology," Physiological Reviews, vol. 87, no. 1, pp. 245-313, 2007.

[93] W. M. Nauseef, "Biological roles for the NOX family NADPH oxidases," The Journal of Biological Chemistry, vol. 283, no. 25, pp. 16961-16965, 2008.

[94] K. Mahadev, H. Motoshima, X. Wu et al., "The NAD(P)H oxidase homolog Nox4 modulates insulin-stimulated generation of $\mathrm{H}_{2} \mathrm{O}_{2}$ and plays an integral role in insulin signal transduction," Molecular and Cellular Biology, vol. 24, no. 5, pp. 1844-1854, 2004.

[95] J. D. Morrow, "Is oxidant stress a connection between obesity and atherosclerosis?" Arteriosclerosis, Thrombosis, and Vascular Biology, vol. 23, no. 3, pp. 368-370, 2003.

[96] M. Kamigaki, S. Sakaue, I. Tsujino et al., "Oxidative stress provokes atherogenic changes in adipokine gene expression in 3T3L1 adipocytes," Biochemical and Biophysical Research Communications, vol. 339, no. 2, pp. 624-632, 2006.

[97] A. F. Soares, M. Guichardant, D. Cozzone et al., "Effects of oxidative stress on adiponectin secretion and lactate production in 3T3-L1 adipocytes," Free Radical Biology and Medicine, vol. 38, no. 7, pp. 882-889, 2005.

[98] T. Sakurai, K. Kitadate, H. Nishioka et al., "Oligomerized grape seed polyphenols attenuate inflammatory changes due to antioxidative properties in coculture of adipocytes and macrophages," Journal of Nutritional Biochemistry, vol. 21, no. 1, pp. 47-54, 2010.

[99] T. Sakurai, H. Nishioka, H. Fujii et al., "Antioxidative effects of a new lychee fruit-derived polyphenol mixture, oligonol, converted into a low-molecular form in adipocytes," Bioscience, Biotechnology and Biochemistry, vol. 72, no. 2, pp. 463-476, 2008.

[100] J. A. McCubrey, M. M. LaHair, and R. A. Franklin, "Reactive oxygen species-induced activation of the MAP kinase signaling pathways," Antioxidants \& Redox Signaling, vol. 8, no. 9-10, pp. 1775-1789, 2006.

[101] Y.-J. Surh, J. K. Kundu, H.-K. Na, and J.-S. Lee, “Redox-sensitive transcription factors as prime targets for chemoprevention with anti-inflammatory and antioxidative phytochemicals," Journal of Nutrition, vol. 135, 12S, pp. 2993S-3001S, 2005.

[102] T. Suganami, K. Tanimoto-Koyama, J. Nishida et al., "Role of the Toll-like receptor $4 / \mathrm{NF}-\kappa \mathrm{B}$ pathway in saturated fatty acid-induced inflammatory changes in the interaction between adipocytes and macrophages," Arteriosclerosis, Thrombosis, and Vascular Biology, vol. 27, no. 1, pp. 84-91, 2007.

[103] F. L. Sung, T. Y. Zhu, K. K. W. Au-Yeung, Y. L. Siow, and O. Karmin, "Enhanced MCP-1 expression during ischemia/ reperfusion injury is mediated by oxidative stress and NF- $\kappa \mathrm{B}$," Kidney International, vol. 62, no. 4, pp. 1160-1170, 2002.

[104] S. Araki, K. Dobashi, K. Kubo, Y. Yamamoto, K. Asayama, and A. Shirahata, "N-acetylcysteine attenuates TNF- $\alpha$ induced changes in secretion of interleukin-6, plasminogen activator inhibitor-1 and adiponectin from 3T3-L1 adipocytes," Life Sciences, vol. 79, no. 25, pp. 2405-2412, 2006.

[105] A. Ito, T. Suganami, Y. Miyamoto et al., "Role of MAPK phosphatase-1 in the induction of monocyte chemoattractant protein-1 during the course of adipocyte hypertrophy," The Journal of Biological Chemistry, vol. 282, no. 35, pp. 2544525452, 2007.
[106] S. P. Helmrich, D. R. Ragland, R. W. Leung, and R. S. Paffenbarger Jr., "Physical activity and reduced occurrence of noninsulin-dependent diabetes mellitus," The New England Journal of Medicine, vol. 325, no. 3, pp. 147-152, 1991.

[107] J. E. Manson, D. M. Nathan, A. S. Krolewski, M. J. Stampfer, W. C. Willett, and C. H. Hennekens, "A prospective study of exercise and incidence of diabetes among US male physicians," JAMA, vol. 268, no. 1, pp. 63-67, 1992.

[108] J. E. Manson, M. J. Stampfer, G. A. Colditz et al., "Physical activity and incidence of non-insulin-dependent diabetes mellitus in women," The Lancet, vol. 338, no. 8770, pp. 774-778, 1991.

[109] R. L. Bradley, J. Y. Jeon, F.-F. Liu, and E. Maratos-Flier, "Voluntary exercise improves insulin sensitivity and adipose tissue inflammation in diet-induced obese mice," American Journal of Physiology-Endocrinology and Metabolism, vol. 295, no. 3, pp. E586-E594, 2008.

[110] V. J. Vieira, R. J. Valentine, K. R. Wilund, N. Antao, T. Baynard, and J. A. Woods, "Effects of exercise and low-fat diet on adipose tissue inflammation and metabolic complications in obese mice," American Journal of Physiology-Endocrinology and Metabolism, vol. 296, no. 5, pp. E1164-E1171, 2009.

[111] T. Sakurai, T. Izawa, T. Kizaki et al., "Exercise training decreases expression of inflammation-related adipokines through reduction of oxidative stress in rat white adipose tissue," Biochemical and Biophysical Research Communications, vol. 379, no. 2, pp. 605-609, 2009.

[112] T. Sakurai, M. Takei, J. Ogasawara et al., "Exercise training enhances tumor necrosis factor- $\alpha$-induced expressions of antiapoptotic genes without alterations in caspase-3 activity in rat epididymal adipocytes," Japanese Journal of Physiology, vol. 55, no. 3, pp. 181-189, 2005.

[113] M. Nara, T. Kanda, S. Tsukui et al., "Running exercise increases tumor necrosis factor- $\alpha$ secreting from mesenteric fat in insulin-resistant rats," Life Sciences, vol. 65, no. 3, pp. 237-244, 1999.

[114] F. S. Lira, J. C. Rosa, A. S. Yamashita, C. H. Koyama, M. L. Batista Jr., and M. Seelaender, "Endurance training induces depotspecific changes in IL-10/TNF- $\alpha$ ratio in rat adipose tissue," Cytokine, vol. 45, no. 2, pp. 80-85, 2009.

[115] J. M. Bruun, J. W. Helge, B. Richelsen, and B. Stallknecht, "Diet and exercise reduce low-grade inflammation and macrophage infiltration in adipose tissue but not in skeletal muscle in severely obese subjects," American Journal of PhysiologyEndocrinology and Metabolism, vol. 290, no. 5, pp. E961-E967, 2006.

[116] T. Christiansen, S. K. Paulsen, J. M. Bruun, S. B. Pedersen, and B. Richelsen, "Exercise training versus diet-induced weight-loss on metabolic risk factors and inflammatory markers in obese subjects: a 12-week randomized intervention study," American Journal of Physiology_Endocrinology and Metabolism, vol. 298, no. 4, pp. E824-E831, 2010.

[117] J. Polak, E. Klimcakova, C. Moro et al., "Effect of aerobic training on plasma levels and subcutaneous abdominal adipose tissue gene expression of adiponectin, leptin, interleukin 6 , and tumor necrosis factor $\alpha$ in obese women," Metabolism: Clinical and Experimental, vol. 55, no. 10, pp. 1375-1381, 2006.

[118] T. Tchkonia, T. Thomou, Y. Zhu et al., "Mechanisms and metabolic implications of regional differences among fat depots," Cell Metabolism, vol. 17, no. 5, pp. 644-656, 2013.

[119] A. Cartier, I. Lemieux, N. Alméras, A. Tremblay, J. Bergeron, and J.-P. Després, "Visceral obesity and plasma glucose-insulin 
homeostasis: contributions of interleukin-6 and tumor necrosis factor- $\alpha$ in men," Journal of Clinical Endocrinology and Metabolism, vol. 93, no. 5, pp. 1931-1938, 2008.

[120] X. J. Xu, M.-S. Gauthier, D. T. Hess et al., "Insulin sensitive and resistant obesity in humans: AMPK activity, oxidative stress, and depot-specific changes in gene expression in adipose tissue," Journal of Lipid Research, vol. 53, no. 4, pp. 792-801, 2012.

[121] G. Tanaka, H. Kato, and T. Izawa, "Endurance exercise training induces fat depot-specific differences in basal autophagic activity," Biochemical and Biophysical Research Communications, vol. 466, no. 3, pp. 512-517, 2015.

[122] T. Suganami, J. Nishida, and Y. Ogawa, "A paracrine loop between adipocytes and macrophages aggravates inflammatory changes: role of free fatty acids and tumor necrosis factor $\alpha$," Arteriosclerosis, Thrombosis, and Vascular Biology, vol. 25, no. 10, pp. 2062-2068, 2005.

[123] I. Harman-Boehm, M. Blüher, H. Redel et al., "Macrophage infiltration into omental versus subcutaneous fat across different populations: effect of regional adiposity and the comorbidities of obesity," Journal of Clinical Endocrinology and Metabolism, vol. 92, no. 6, pp. 2240-2247, 2007.

[124] K. S. C. Gollisch, J. Brandauer, N. Jessen et al., "Effects of exercise training on subcutaneous and visceral adipose tissue in normal- and high-fat diet-fed rats," American Journal of Physiology-Endocrinology and Metabolism, vol. 297, no. 2, pp. E495-E504, 2009.

[125] M. Moghadasi, H. Mohebbi, F. Rahmani-Nia, S. Hassan-Nia, H. Noroozi, and N. Pirooznia, "High-intensity endurance training improves adiponectin mRNA and plasma concentrations," European Journal of Applied Physiology, vol. 112, no. 4, pp. 12071214, 2012.

[126] S. Miyazaki, T. Izawa, J.-E. Ogasawara et al., "Effect of exercise training on adipocyte-size-dependent expression of leptin and adiponectin," Life Sciences, vol. 86, no. 17-18, pp. 691-698, 2010.

[127] T. Skurk, C. Alberti-Huber, C. Herder, and H. Hauner, "Relationship between adipocyte size and adipokine expression and secretion," The Journal of Clinical Endocrinology \& Metabolism, vol. 92, no. 3, pp. 1023-1033, 2007.

[128] N. Maeda, M. Takahashi, T. Funahashi et al., "PPAR $\gamma$ ligands increase expression and plasma concentrations of adiponectin, an adipose-derived protein," Diabetes, vol. 50, no. 9, pp. 20942099, 2001.

[129] K.-Y. Guo, P. Halo, R. L. Leibel, and Y. Zhang, "Effects of obesity on the relationship of leptin mRNA expression and adipocyte size in anatomically distinct fat depots in mice," American Journal of Physiology-Regulatory Integrative and Comparative Physiology, vol. 287, no. 1, pp. R112-R119, 2004.

[130] Y. Zhang, K.-Y. Guo, P. A. Diaz, M. Heo, and R. L. Leibel, "Determinants of leptin gene expression in fat depots of lean mice," American Journal of Physiology-Regulatory Integrative and Comparative Physiology, vol. 282, no. 1, pp. R226-R234, 2002.

[131] J. M. de Farias, K. F. Bom, C. B. Tromm et al., "Effect of physical training on the adipose tissue of diet-induced obesity mice: interaction between reactive oxygen species and lipolysis," Hormone and Metabolic Research, vol. 45, no. 3, pp. 190-196, 2013.

[132] J. Ko and K. Kim, "Effects of exercise and diet composition on expression of MCP-1 and oxidative stress-related mRNA of adipose tissue in diet-induced obese mice," Journal of Exercise Nutrition and Biochemistry, vol. 17, no. 4, pp. 181-188, 2013.
[133] N. Ferrara, B. Rinaldi, G. Corbi et al., "Exercise training promotes SIRT1 activity in aged rats," Rejuvenation Research, vol. 11, no. 1, pp. 139-150, 2008.

[134] N. Ahn and K. Kim, "Combined influence of dietary restriction and treadmill running on MCP-1 and the expression of oxidative stress-related mRNA in the adipose tissue in obese mice," Journal of Exercise Nutrition and Biochemistry, vol. 18, no. 3, pp. 311-318, 2014.

[135] C. E. Cooper, N. B. Vollaard, T. Choueiri, and M. T. Wilson, "Exercise, free radicals and oxidative stress," Biochemical Society Transactions, vol. 30, no. 2, pp. 280-285, 2002.

[136] S. K. Powers, L. L. Ji, A. N. Kavazis, and M. J. Jackson, "Reactive oxygen species: impact on skeletal muscle," Comprehensive Physiology, vol. 1, no. 2, pp. 941-969, 2011.

[137] L. L. Ji, "Modulation of skeletal muscle antioxidant defense by exercise: role of redox signaling," Free Radical Biology and Medicine, vol. 44, no. 2, pp. 142-152, 2008.

[138] L. L. Ji, M.-C. Gomez-Cabrera, and J. Vina, "Exercise and hormesis: activation of cellular antioxidant signaling pathway," Annals of the New York Academy of Sciences, vol. 1067, no. 1, pp. 425-435, 2006.

[139] C. K. Sen, "Antioxidants in exercise nutrition," Sports Medicine, vol. 31, no. 13, pp. 891-908, 2001.

[140] D. B. Pyne, "Exercise-induced muscle damage and inflammation: a review," Australian Journal of Science and Medicine in Sport, vol. 26, no. 3-4, pp. 49-58, 1994.

[141] J. M. Sacheck and J. B. Blumberg, "Role of vitamin E and oxidative stress in exercise," Nutrition, vol. 17, no. 10, pp. 809814, 2001.

[142] S. K. Powers, W. B. Nelson, and M. B. Hudson, "Exerciseinduced oxidative stress in humans: cause and consequences," Free Radical Biology and Medicine, vol. 51, no. 5, pp. 942-950, 2011.

[143] V. S. Pereira Panza, F. Diefenthaeler, and E. L. da Silva, "Benefits of dietary phytochemical supplementation on eccentric exercise-induced muscle damage: is including antioxidants enough?” Nutrition, vol. 31, no. 9, pp. 1072-1082, 2015.

[144] W. Aoi, Y. Naito, Y. Takanami et al., "Oxidative stress and delayed-onset muscle damage after exercise," Free Radical Biology \& Medicine, vol. 37, no. 4, pp. 480-487, 2004.

[145] C. Leeuwenburgh, R. Fiebig, R. Chandwaney, and L. L. Ji, "Aging and exercise training in skeletal muscle: responses of glutathione and antioxidant enzyme systems," American Journal of Physiology-Regulatory Integrative and Comparative Physiology, vol. 267, no. 2, pp. R439-R445, 1994.

[146] M. Higuchi, L. J. Cartier, M. Chen, and J. O. Holloszy, "Superoxide dismutase and catalase in skeletal muscle: adaptive response to exercise," Journals of Gerontology, vol. 40, no. 3, pp. 281-286, 1985.

[147] S. K. Powers, D. Criswell, J. Lawler et al., "Influence of exercise and fiber type on antioxidant enzyme activity in rat skeletal muscle," American Journal of Physiology, vol. 266, no. 2, pp. R375-R380, 1994.

[148] J. C. Dekkers, L. J. P. Van Doornen, and H. C. G. Kemper, “The role of antioxidant vitamins and enzymes in the prevention of exercise-induced muscle damage," Sports Medicine, vol. 21, no. 3, pp. 213-238, 1996. 


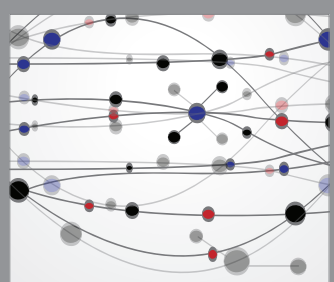

The Scientific World Journal
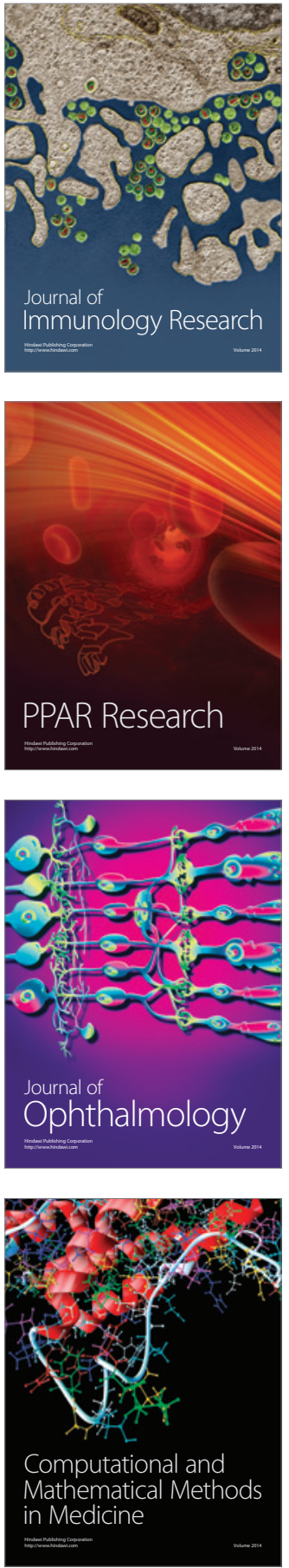

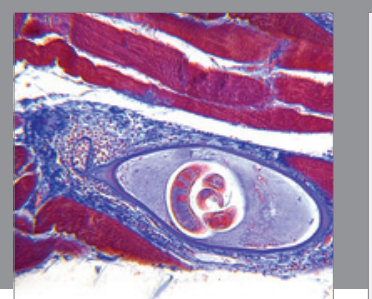

Gastroenterology Research and Practice
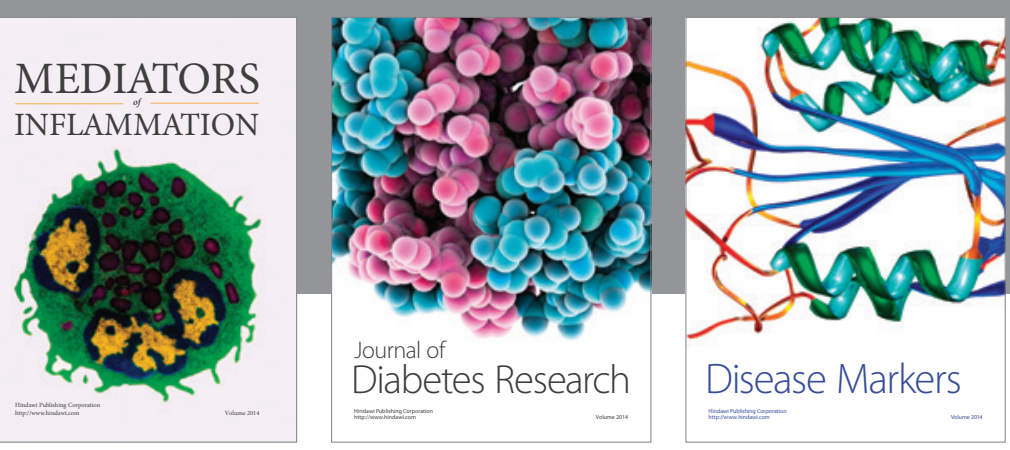

Disease Markers

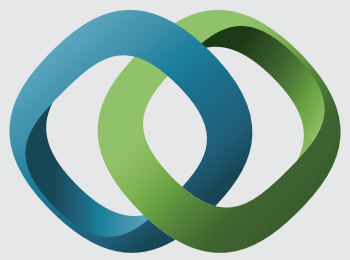

\section{Hindawi}

Submit your manuscripts at

https://www.hindawi.com
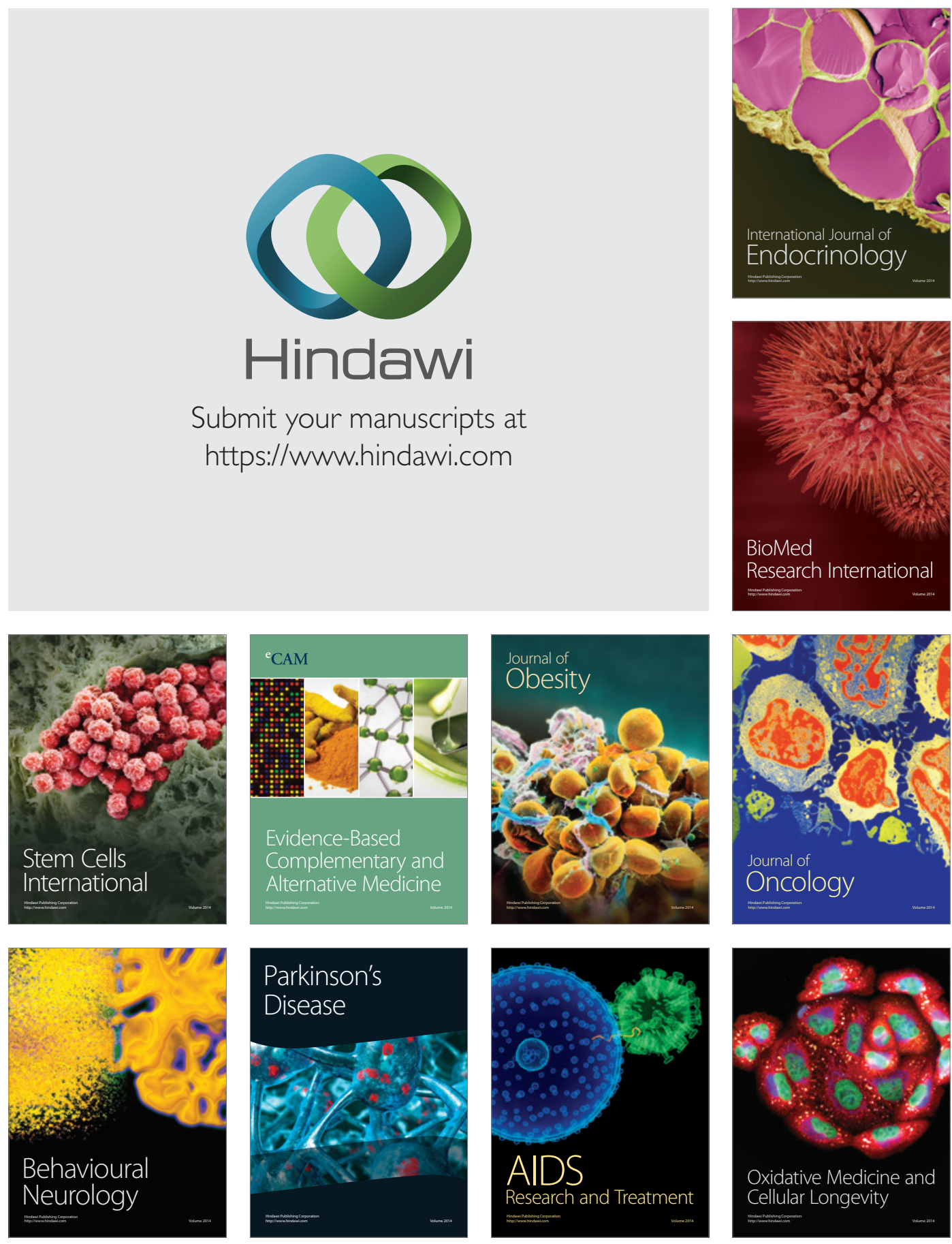